\title{
A Research Paper on A Case Series on Clinical Presentation of Tuberculous Meningitis.
}

\author{
Dr. Bharat Veer Manchanda ${ }^{1}$,Dr. Girish Dubey ${ }^{2}$,Dr. Saloni Mehra ${ }^{3}$,Dr. Umesh \\ Verma $^{4}$,Dr. Saminder Chaudhary ${ }^{5}$, Dr. Arun Khatri ${ }^{6}$ \\ ${ }^{1}$ Assi. Professor In Dept Of Medicine, Subharti Medical College, Meerut \\ ${ }^{2,4,5,6}$ Post Graduate In Dept Of Medicine, Subharti Medical College, Meerut \\ ${ }^{3}$ Post Graduate In Dept Of Surgery, Subharti Medical College, Meerut
}

\section{Introduction}

Tuberculosis which is caused by bacteria of the mycobacterium tuberculosis complex, is one of the oldest disease known to affects humans and a major cause of death worldwide. Tuberculosis of cns results from the hematogenous spread of primary or post primary $\mathrm{TB}$ or from the rupture of subependymal tubercule into the subarachnoid space.In more than half of the cases, evidence of old pulmonary lesion or a military pattern is found on chest radiography. The disease often present subtly as headache and slight mental changes after a prodrome of weeks of low grade fever, malaise, anorexia and irritability. If not recognized, tuberculous meningitis may evolve acutely with severe headache, confusion, lethargy, altered sensorium and neck rigidity.

Typically the disease evolves over 1-2 weeks a course longer than that of bacterial meningitis because meningeal involvement is pronounced at the base of the brain,paresis of cranial nerves(ocular nerve in particular) is a frequent finding and involvement of cerebral arteries may produce focal ischemia. The ultimate evolution is toward coma with hydrocephalous and raise intracranial pressure.

Tuberculosis is one of the leading cause of mortality and morbidity in developing countries.

Early diagnosis and treatment with chemotheraphy and active management of the complications are of great importance to prevent the irreversible neurological sequale and death. Delay in diagnosis and so in the start of effective treatment results in poor prognosis and sequel in upto $25 \%$ cases.Diagnosis of TBM depends on csf so, Lp is the cornerstone of diagnosis. In genral examination of csf reveals high leukocyte count usually with predominance of lymphocytes but some times with a predominance of neutrophils in the early stage. A protein content of $1-8 \mathrm{~g} / \mathrm{l}(100-800 \mathrm{mg} / \mathrm{dl})$ and a low glucose level.AFB's are infrequently seen on direct smear of csf sediment.culture of csf is diagnostic in upto $80 \%$ of cases and remain the gold standard.

\section{Material And Method}

This was an observational study which was performed on patients admitted in C.S.S.H Subharti Medical College , Meerut U.P.A total 30 number of patients were enrolled in this study from AUG 2016-JAN 2017. All patients whose history,clinical manifestations and csf findings were suggestive of TBM were included in this study.Detailed history and clinical examination with duration of illness, clinical manifestation (fever, headache, vomiting, anorexia, weight loss , altered sensorium, neck stiffness) were noted. In laboratory investigations $\mathrm{Cbc}$, lft, rft, fever profile, urine routine/microscopy, chest xray, usg(w/a) ncct head , fundus examination and lumbar puncture were done on cas to case bases.

\section{Results}

Distribution According To Age

\begin{tabular}{|l|l|l|}
\hline Age & Frequency & Percentage \\
\hline 18-30 Years & 14 & $46.6 \%$ \\
\hline $30-40$ Years & 8 & $26.6 \%$ \\
\hline 40-50 Years & 5 & $16.6 \%$ \\
\hline$>50$ Years & 3 & $10 \%$ \\
\hline
\end{tabular}

Distribution Accoring To Sex

\begin{tabular}{|l|l|l|}
\hline Sex & Frequency & Percentage \\
\hline Male & 18 & $60 \%$ \\
\hline Female & 12 & $40 \%$ \\
\hline
\end{tabular}


A Research Paper On A Case Series On Clinical Presentation Of Tuberculous Meningitis.

\begin{tabular}{|l|l|l|}
\multicolumn{2}{|c|}{ Distribution According To Presenting Complains } \\
\hline Symptom & Frequency & Percentage \\
\hline Fever & 18 & $60 \%$ \\
\hline Vomitting & 13 & $43.3 \%$ \\
\hline Headache & 24 & $80 \%$ \\
\hline Convulsion & 3 & $10 \%$ \\
\hline $\begin{array}{l}\text { Anorexia,Weight } \\
\text { Loss }\end{array}$ & 7 & 23.3 \\
\hline Altered Sensorium & 6 & $20 \%$ \\
\hline
\end{tabular}

Distribution of the study subjects by presenting symptoms the most prevalent symptom were headache (80\%), fever $(60 \%)$, vomiting $(43.3 \%)$.

Distribution According To Physical Sign

\begin{tabular}{|l|l|l|}
\hline & Frequency & Percentage \\
\hline Anemia & 9 & $30 \%$ \\
\hline Neck Rigidity & 13 & $43.3 \%$ \\
\hline Cranial Nerve Palsy & 0 & 0 \\
\hline
\end{tabular}

Distribution According To Fundus Examiantion

\begin{tabular}{|l|l|l|}
\hline & FREQUENCY & PERCENTAGE \\
\hline Normal & 24 & $80 \%$ \\
\hline Papilloedema & 6 & $20 \%$ \\
\hline Optic Atrophy & 0 & \\
\hline
\end{tabular}

\section{Discussion}

The present study was done on Tubercular meningitis patients. The aim of the study focussed on clinical manifestations of tubercular meningitis and presentation of tubercular meningitis and distribution of tubercular meningitis according to age and sex. The study was done on 30 patients and the inclusion criteria was based on CSF findings(high leukocyte count, high protein and low sugar).

The conclusion of our study was that the most prominent clinical manifestation of tubercular meningitis was headache $80 \%$ (24 out of 30 patients) and which was associated with vomiting $43.3 \%$ (13 out of 30 ). The other cause of headache were ruled out (eg. Migraine, Refractory disorder).Fever was the $2^{\text {nd }}$ most prominent clinical manifestation $60 \%$ after headache. Fever was low grade, more in evening. There patient give history of long term fever(2-3 months) along with fever there patient complain of anorexia, weight $\operatorname{loss}(23.3 \%)$ Literature tolds that fever can be absent in upto $25 \%$ of patients. Convulsion were present in $10 \%(3$ pts)( tonic \& clonic type. In one study the incidence of convulsion was $12.1 \%$.The meningeal sign which were noted in these patients were present as neck rigidity(40\%)There have been studies that have reported neck rigidity upto 54\%.In present study Papilloedema was present in $20 \%$ of cases.

Acc to the present study the incidence in males was upto $60 \%$ and in females upto $40 \%$. There have been studies in which incidence in males and females is consistent. The reason for high prevelance ofTBM among the male can be explained as male are more exposed as they are the earning member of family, so they have more chances to get infection and all of these patients male and female, most of them were from low socio economic status. All these 30 patients were taken on ATT out of which 26 pts responded well and are in follow up. 4 patients did not respond to treatment and expired.

TBM is a severe form of extrapulmonary tuberculosis occurring in 7-12\% of tb patients in developing countries with high rate of mortality due to delay in diagnosis and proper treatment. In the absence of an early diagnosis and treatment, tuberculous meningitis is characterized by high mortality(20-50\%) and morbidity (20$30 \%)$. So, early diagnosis and active management should be done in patients with TBM in order to reduce mortality and morbidity. 